\title{
MOGUĆNOSTI PRIMENE INSTRUMENATA UPITNIČKOG TIPA NAMENJENIH SAMOPROCENI KAPACITETA ZA SAMOZASTUPANJE OSOBA SA INTELEKTUALNIM TEŠKOĆAMA ${ }^{\prime}$
}

\author{
Boban Petrović́ , Katarina Tadić, Duška Stojisavljević
}

Asocijacija za promovisanje inkluzije Srbije - API Srbije, Beograd

U poslednjih desetak godina, u skladu sa filozofijom inkluzije, sve veća pažnja posvećuje se mogućnosti upitničke samoprocene osobama sa intelektualnim teškoćama u pogledu različitih psiholoških konstrukata. Medutim, podaci su razliciti, od onih koji ukazuju na nemogućnost dobijanja pouzdanih $i$ validnih odgovora na upitnicima, do onih koji pokazuju da upitnici namenjeni samoproceni OSIT mogu imati adekvatnu pouzdanost $i$ validnost.

Osnovni cilj ovog istraživanja ticao se ispitivanja mogućnosti dobijanja pouzdanih $i$ validnih podataka na osnovu samoprocene osoba sa intelektualnim teškoćama na setu različitih instrumenata namenjenih ispitivanju kapaciteta za samozastupanje.

U tom smislu, na uzorak od 35 osoba sa intelektualnim teškoćama različitog pola, starosti, tipa i stepena teškoća, primenjen je set od 6 instrumenata namenjenih samoproceni: samopoštovanja, samoodlučivanja, vršenja izbora, rešavanja problema, poznavanja prava $i$ samoodređenja. Podaci su obradeni analizom glavnih komponenti, kao i programom RTT10G za utvrdivanje metrijskih karakteristika instrumenata.

Rezultati pokazuju da, uprkos blagom narušavanju pri drugom merenju, instrumenti poseduju adekvatne metrijske karakteristike (reprezentativnost, homogenost i pouzdanost), te da se radi o jednodimenzionalnim ins-

\footnotetext{
${ }^{1}$ Ovo istraživanje nastalo je kao rezultat evaluacije projekta 209/08-7, finansiranog od strane Ministarstva za rad i socijalnu politiku republike Srbije

2 boban@sapi.rs
} 
trumentima. Stoga, može se reći da postoji mogućnost pouzdane i validne upitničke samoprocene različitih dimenzija samoodređenja i samozastupanja kod osoba sa intelektualnim teškoćama.

Ključne reči: osobe sa intelektualnim teškoćama, samozastupanje, upitnici, samoprocena, metrijske karakteristike

\section{Uvod}

U zadnjih dvadesetak godina, sa sve većom zastupljenošću filozofije inkluzije, i, samim tim, pokreta socijalnog uključivanja, sve više se poklanja pažnja ljudskim pravima, pa i pravima osoba sa intelektualnim teškoćama.

Sam termin "intelektualne teškoće" jedan je od mnogih termina, poput mentalne retardacije, mentalne zaostalosti, ometenosti u mentalnom razvoju, i slično, koji se koriste za označavanje specifičnog stanja jedne subpopulacije, koja se, prema standardnoj psihometrijskoj klasifikaciji, zasnovanoj na normalnoj distribuciji inteligencije u populaciji, nalazi 2,3 standardne devijacije ispod proseka (prema: Campbell, 2001).

Verovatno najrašireniji termin je "mentalna retardacija", pod kojom se, prema definiciji Američke asocijacije za mentalnu retardaciju (American Association on Mental Retardation, AAMR) podrazumevaju teškoće koje nastaju pre 18. godine, koje karakterišu značajna ograničenja i intelektualnom funkcionisanju i adaptivnom ponašanju, i koje se ogledaju u konceptualnim, socijalnim i praktičnim adaptivnim veštinama (AMMR, 1992, prema: Garaigordobil, Pérez, 2007). Međutim, upravo je Američka asocijacija za mentalnu retardaciju predložila novi, obuhvatniji model objašnjenja i definisanja intelektualnih teškoća, koji ne podrazumeva prostu linearnu povezanost sa IQ-om, već ukazuje da teškoće mogu imati različito poreklo, i zahtevati različite resurse za prevladavanje, uključujući različite oblike i nivoe podrške, koji su usmereni na lični razvoj, obrazovanje, interesovanja i ličnu dobrobit, i koji doprinose povećanju nivoa individualnog funkcionisanja u sredini u kojoj pojedinac sa intelektualnim teškoćama živi. Upravo zbog potrebe za celovitim sagledavanjem intelektualnih teškoća, Američka asocijacija za intelektualne teškoće* razvila je multidimenzionalni model intelektualnih teškoća (prema: Gustaffson, 2003), koji uključuje pet uzajamno povezanih dimenzija. To su: intelektualne sposobnosti (dimenzija I), adaptivno ponašanje (dimenzija II), participacija, interakcija i

\footnotetext{
* American Association of Intellectual Disabilities, naziv koji je od 2005 godine usvojila Američka asocijacija za mentalnu retardaciju - American Association of Mental Retardation
} 
socijalne uloge (dimenzija III), zdravlje (dimenzija IV) i kontekst (dimenzija $\mathrm{V})$.

U tom, smislu, poseban akcenat se stavlja na prava osoba sa intelektualnim teškoćama na ličnu participaciju u svim socijalnim procesima koji se tiču njih samih. Važnost ovih procesa je pre svega u tome što je polako dolazi do promene u percepciji osoba sa intelektualnim teškoćama u pravcu uvažavanja njih kao, pre svega, osoba (Wright, 1969, prema: Petrović, 2008). Ovi procesi imaju svoje implikacije i u pogledu uključivanja osoba sa intelektualnim teškoćama u proces naučnog ispitivanja različitih psihičkih i drugih fenomena.

$\mathrm{U}$ tom smislu, primetni su pokušaji usmereni na ispitivanje kompetentnosti i pozitivnih aspekata ličnosti osoba sa intelektualnim teškoćama, kao i primene instrumenata za procenu ličnosti u celini, poput NEO PI R-a, operacionalizacije petofaktorskog modela ličnosti (Petrović, 2008; Lindsay, Rzepecka, Law, 2007). Pored toga, akcenat polako počinje da se stavlja na skale procene i samoprocene osoba sa intelektualnim teškoćama, mada se i dalje instrumenti prevashodno razvijaju za potrebe (samo)procene različitih mentalnih teškoća psihijatrijskog tipa. Najveći broj instrumenata razvijen je za procenu i samoprocenu depresivnosti, anksioznosti, i agresivnosti. Takođe, najveći broj ovih, pretežno jednodimenzionalnih instrumenata, prema izveštajima autora, poseduje zadovoljavajuće metrijske karakteristike (interne konzistentnosti, testretest pouzdanosti, konstruktivne i diskriminativne validnosti). Tako, na primer, što se tiče skala procene, Esbensen, Rojahn, Aman, i Ruedrich (2003), pokazuju dobre metrijske karakteristike Skale za procenu anksioznosti, depresivnosti i poremećaja raspoloženja (ADAMS), a Meins $(1993,1996)$ ukazuje na zadovoljavajuće metrijske karakteristike Inventara depresivnosti za decu modifikovanog za upotrebu sa osobama sa intelektualnim teškoćama. Što se tiče skala samoprocene, takođe postoje slični podaci. Reynolds i Baker (1988) izveštavaju o dobrim metrijskim karakteristikama instrumenta za samoprocenu depresivnosti (Self-Report Depression Questionnaire), čija je pouzdanost .90 , a test-retest pouzdanost .63. Za Bekov modifikovani inventar depresivnosti, prilagođen osobama sa intelektualnim teškoćama, takođe postoje podaci o zadovoljavajućoj test-retest pouzdanosti (Beck et al., 1996). Takođe su razvijene skale za samoprocenu depresivnosti i anksioznosti osoba sa intelektualnim teškoćama, poznate pod nazivom Glasgow Depression Scale for people with Learning Ddisability (Cuthill, Espie, Cooper, 2003), i Glasgow Anxiety Scale for people with Learning Disability (Mindham, Espie, 2003), za koje autori navode adekvatne metrijske karakteristike.

Međutim, postoji i dosta radova koji ukazuju na različite metodološke teškoće u pogledu mogućnosti upitničke (samo)procene osoba sa intelektualnim teš- 
koćama; najčešće se navode problemi sa niskom pouzdanošću (Tailor, 2002), merama validnosti, naročito sa konstrukt-validnošću (Torr, 2003; Davis, Judd and Herrman, 1997a; Davis, Judd and Herrman, 1997b; Mindham, Espie, 2003), i uopšte psihometrijskim karakteristikama instrumenata. Ali, javljaju se i drugačiji problemi, kao što su: sadržaji ajtema, način formulisanja ajtema, format odgovora (Finlay, Lyons, 2001; Wyngaarden, 1981; Heal, Sigelman, 1995), načini odgovaranja ispitanika sa intelektualnim teškoćama (Matikka, Vesala, 1997; Hartley, MacLean, 2006; Sigelman, Budd, Winer, Schoenrock, Martin, 1982; Heal, Sigelman, 1995). Pri tome je primećeno da osobe sa lakšim intelektualnim teškoćama mogu odgovarati na klasične samoopisne tehnike, bez, ili sa malo modifikacija, sa odgovorima koji ne odstupaju mnogo od odgovora tipičnih osoba, dok kod onih sa većim teškoćama dolazi i do većih odstupanja u načinu i kvalitetu razumevanja ajtema i odgovora na njih (Hurley, 2006; Sigelman, Schoenrock, Spanhel, Hromas, Winer, Budd, Martin, 1980). Ipak, postoje i nalazi koji ukazuju na mogućnost primene samoopisnih tehnika kod osoba sa intelektualnim teškoćama čiji je IQ $>=48$ (Douma, Dekker, Verhulst, Koot, 2006).

Jedan od metodoloških problema na koji autori često ukazuju (Wehmeyer,1994, Hartley, Mac Lean, 2006), je sklonost ka davanju pozitivnih odgovora na stavkama dihotomnog izbora (da-ne; tačno-netačno). Međutim, postoje podaci koji pokazuju da nema značajnih razlika između adolescenata sa i bez intelektualnih teškoća u tendenciji davanja pozitivnih odgovora, kao i da ne postoji značajna povezanost ove tendencije i količnika inteligencije (Ramirez, 2005).

Značajan problem predstavlja i izbor formata odgovora. Iako se u slučaju samoprocena kod osoba sa intelektualnim teškoćama najčešće koristi dihotomni izbor (da/ne, tačno/netačno) (Hartley, Mac Lean, 2006, Cuthill, Espie, Copper, 2003), postoje podaci koji ukazuju na mogućnost upotrebe skala sa više ponuđenih odgovora. Pri tome, smatra se da najpouzdaniju i najvalidniju procenu daju rezultati sa trostepenom skalom (Cuthill, Espie, Copper, 2003), koja omogućava procenu šireg opsega varijanse od skala dihotomnog tipa, i pokazuje bolju stabilnost u vremenu, a lakša je za razumevanje od četvoro-ili petostepene skale.

Jedno od ključnih pitanja upravo je pitanje principa na kojima treba zasnovati izbor ili konstrukciju instrumenta za samoprocenu osoba sa intelektualnim teškoćama. Kao opšta preporuka često se navodi da treba, kad god je to moguće, primeniti instrumente koji se mogu aplicirati bez modifikacije ili ispuštanja pojedinih ajtema ili subskala u celini (Hrnjica, 1991). Međutim, napred smo izložili da ovaj pristup ne daje adekvatna rešenja. Alternativno rešenje se 
sastoji u konstrukciji instrumenata koji će biti prilagođeni osobama sa intelektualnim teškoćama. Konstrukcija ovih instrumenata treba da bude zasnovana na nekoliko opštih preporuka (Hrnjica, 1991; Finlay, Lyons, 2001; Davis, Judd and Herrman, 1997; Petrović, Novak, 2009): instrumenti treba da su prilagođeni populaciji koja se ispituje; treba da omogućuju dvosmernu komunikaciju, odnosno, da se distribuiraju u obliku strukturiranog intervjua; treba da podstaknu one procese koji su vezani za procenu; treba da budu relativno kratki, da skala bude trostepena, te da se mere jednodimenzionalni konstrukti.

U skladu sa opštim principom socijalnog uključivanja, u Srbiji je počeo da se razvija pokret samozastupanja osoba sa intelektualnim teškoćama. Samozastupanje predstavlja društveni pokret, zahvaljujući kome su osobe sa intelektualnim teškoćama zauzele značajnu ulogu u borbi za ostvarivanje svojih prava. Za osobe sa intelektualnim teškoćama, samozastupanje znači da mogu govoriti za sebe i donositi odluke bitne za njihov život, bilo direktno ili uz podršku.

Samozastupanje osoba sa intelektualnim teškoćama obuhvata deo ličnog identiteta. $\mathrm{Na}$ individualnom planu, samozastupanje uključuje napore pojedinca da govori i radi u svoje ime, da donosi odluke i utiče na situacije koje se tiču njegovog života, kao i da postigne najveće mogući stepen nezavisnosti (Atkinson, 2002).

Iz toga razloga, postoji potreba za procenom kompetentnosti za samozastupanje osoba sa intelektualnim teškoćama, te se nameće pitanje da li je moguće razviti takav set instrumenata namenjenih samoproceni osoba sa intelektualnim teškoćama koji će omogućiti dobijanje pouzdanih i validnih podataka.

\section{Cilj istraživanja}

Shodno napred navedenom, osnovni cilj ovog istraživanja tiče se ispitivanja mogućnosti dobijanja pouzdanih i validnih podataka na osnovu samoprocena osoba sa intelektualnim teškoćama na setu različitih instrumenata upitničkog tipa namenjenih ispitivanju kapaciteta za samozastupanje.

\section{Metod}

\section{Instrumenti}

U istraživanju su primenjeni sledeći instrumenti.

SPROSIT S - upitnik namenjen proceni samopoštovanja (prema: Bilić, 2000); upitnik se sastoji od 17 ajtema (na primer: "Da li si zadovoljan/na sobom?"; 
"Da li jednako vrediš kao i drugi ljudi?"; "Da li se dopadaš sam sebi?"), kojima je pridružena 3-stepena skala.

SDU - Upitnik za procenu samoodređenja (Clark, Patton, 1998); upitnik se sastoji od 16 ajtema (na primer: "Ja znam u čemu sam dobar, i mogu to da nabrojim"; "Ja znam kad mi treba pomoć, i od koga da je zatražim"); ajtemima je pridružena 3-stepena skala.

SOD - Upitnik za procenu samoodlučivanja (prema: Bilić, 2000) obuhvata 12 ajtema, sa pridruženom 3-stepenom skalom; primeri ajtema su: "Da li sam odlučiš šta ćeš da jedeš?"; "Da li ideš u šetnju kad ti to želiš?".

VIDO - Intervju za procenu vršenja izbora i donošenja odluka (prema: Kraljević, 2001); namenjen je utvrđivanju nivoa usvojenosti veština vršenja izbora i donošenja odluka osoba s intelektualnim teškoćama. Sastoji se od osam varijabli (na primer: "Koja ti se od ove odeće najviše sviđa? Zašto?"; "Koji ti se od ovih sportova najviše sviđa? Zašto?"), od kojih svaka predstavlja jednu izbornu situaciju u kojoj se ispitanik mora odlučiti za jednu od ponuđenih mogućnosti, te obrazložiti svoj izbor. Na svakoj varijabli ispitanik može dobiti 0,1 ili 2 boda, u zavisnosti od kvaliteta odgovora.

VRPI - Intervju za procenu nivoa usvojenosti veština rešavanja problema (prema: Kraljević, 2001) sastoji od 6 ajtema od kojih svaka predstavlja jednu problemsku situaciju koju ispitanik mora da reši (na primer, ”Tvoji prijatelji se ponašaju kao da se ljute na tebe. Želiš da se pomiriš s njima. Šta ćeš da uradiš?"). Na svakom ajtemu ispitanik može dobiti 0, 1 ili 2 boda. Ukoliko ispitanik ne može da sagleda problem, ne nudi nikakav način za rešenje ili jednostavno ponovi date informacije bez rešavanja situacije dobija 0 bodova. Ukoliko sagledava problem ali ne može pružiti rešenje dobija 1 bod, a ukoliko ponudi adekvatno rešenje problema dobija 2 boda.

PRAVA - Upitnik za procenu svesti o sopstvenim pravima (prema: Kraljević, 2001; Parker, Goedhart, Gomez, 2004) sadrži 10 ajtema, kojima je pridružena 2-stepena (u prvom) odn., trostepena (u drugom ispitivanju) skala. Primeri ajtema: "Važno je znati svoja prava.", "Ako imaš teškoće, nemaš pravo da glasaš.”.

Svi navedeni instrumenti prevedeni su i prilagođeni za upotrebu (Petrović, Novak, 2009) za populaciju osoba sa intelektualnim teškoćama. 


\section{Procedura ispitivanja}

Svi instrumenti primenjeni su individualno, od strane ispitivača koji je osobi poznat i s kojim je prethodno uspostavljena komunikacija i atmosfera međusobnog poverenja. Instrumenti su administrirani kao strukturisani intervjui, zbog toga što osobe sa intelektualnim teškoćama u velikom broju slučajeva imaju teškoće sa čitanjem. Ispitanici su prvo odgovarali na svaku tvrdnju sa Da i Ne, izražavajući slaganje ili neslaganje s tvrdnjom. Nakon toga, ukoliko je ispitanik odgovorio sa Da, morao je da izabere jednu od dve mogućnosti: ponekad/malo, ili uvek/mnogo, u zavisnosti od sadržaja ajtema. Na taj način, omogućena je primena trostepene skale, i povećan varijabilitet odgovora (videti: Cuthill, Espie, Cooper, 2003). Instrumenti su administrirani dva puta, s tim što je retest realizovan 6 meseci nakon prvog ispitivanja.

\section{Uzorak}

Ispitivanje je realizovano na uzorku od 35 osoba sa intelektualnim teškoćama, različitog pola (muški-14(40\%), ženski-21(60\%)), starosti (19-58 godina, $\mathrm{AS}=31.4, \mathrm{SD}=8.97$ ) i stepena intelektualnih teškoća (lake IT-10(28.6\%), umerene IT-25(71.4)).

\section{Obrada podataka}

Obrada podataka zasnovana je na analizi glavnih komponenti, kojom je utvrdivana dimenzionalnost i faktorska validnost instrumenata, dok su metrijske osobine instrumenata (pouzdanost, homogenost i reprezentativnost) utvrđene na osnovu programa RTT10G (Knežević, Momirović, 1996).

\section{Rezultati}

Rezultati ispitivanja faktorske strukture instrumenata, odnosno, njihove potencijalne jednodimenzionalnosti prikazani su u Tabelama 1. i 2., kao i u Grafikonima 1. i 2., koji se nalaze u prilogu. 
Tabela 1. Dimenzionalnost instrumenata pri prvom testiranju na osnovu Gutman-Kajzerovog kriterijuma

\begin{tabular}{|c|c|c|c|c|c|}
\hline \multirow[t]{2}{*}{ Instrumenti } & \multirow[t]{2}{*}{ Br. GK } & \multicolumn{2}{|c|}{$\lambda$ - svojstvene vrednosti } & \multicolumn{2}{|c|}{$\%$ varijanse } \\
\hline & & IGK & (II GK) & IGK & (II GK) \\
\hline SPROSIT & 5 & 6.132 & $(2.455)$ & 36.1 & $(14.4)$ \\
\hline SDU & 3 & 9.464 & (1.395) & 59.1 & (8.7) \\
\hline SOD & 3 & 4.250 & (2.063) & 35.4 & $(17.2)$ \\
\hline VIDO & 1 & 5.705 & $(.784)$ & 71.3 & (9.8) \\
\hline VRPI & 1 & 4.079 & $(.658)$ & 68.0 & $(10.9)$ \\
\hline PRAVA & 4 & 3.237 & (1.628) & 32.4 & (16.3) \\
\hline
\end{tabular}

Značenje skraćenica u tabeli: SPROSIT S - upitnik namenjen proceni samopoštovanja; SDU Upitnik za procenu samoodređenja; SOD - Upitnik za procenu samoodlučivanja; VIDO - Intervju za procenu vršenja izbora i donošenja odluka; VRPI - Intervju za procenu nivoa usvojenosti veština rešavanja problema; PRAVA - Upitnik za procenu svesti o sopstvenim pravima; Br. GK - broj glavnih komponenti; I GK - Prva glavna komponenta; II GK- Druga glavna komponenta

Na podacima prikupljenim pri prvoj administraciji seta instrumenata za procenu kapaciteta za samozastupanje, primenjena je analiza glavnih komponenti. Na osnovu Gutman-Kajzerovog kriterijuma, samo u slučaju dva instrumenta (VIDO i VRPI) ekstrahovana je po jedna jasna glavna komponenta, koji objašnjava u oba slučaja oko $70 \%$ varijanse. Za sve druge instrumente, GutmanKajzerov kriterijum (Tabela 1.) sugerisao je postojanje većeg broja glavnih komponenti. Međutim, značajno je primetiti da u svim slučajevima svojstvena vrednost prve glavne komponente nije manja od 3.000, i vrednost $\lambda$ prve glavne komponente je primetno veća $u$ odnosu na $\lambda$ druge ekstrahovane glavne komponente; takođe je značajno primetiti da prva glavna komponenta kod svih instrumenata objašnjava preko $30 \%$ varijanse. Međutim, Katelov Scree test (Grafikon 1.) kod svih instrumenata sugeriše ili jasno naglašava jednu dominantnu glavnu komponentu.

Stoga se, na osnovu ove analize, može zaključiti da se instrumenti mogu smatrati jednodimenzionalnim.

Međutim, analiza glavnih komponenti na podacima prikupljenim istim setom instrumenata pri drugom merenju pokazuje da je došlo do značajnog narušavanja jednodimenzionalnosti instrumenata. Na to ukazuje u većoj meri broj ekstrahovanih glavnih komponenti na osnovu Gutman-Kajzerovog kriterijuma (Tabela 2.), dok Katelov scree kriterijum (Grafikon 1.) ukazuje na značajno narušavanje jednodimenzionalnosti samo kod 2 instrumenta (SPROSIT i SOD), kod kojih, međutim, i pri prvom merenju podaci nisu ukazivali na jasnu jednodimenzionalnost. 
Međutim, ovde je značajno primetiti da je kod jednog instrumenta, PRAVA, došlo do značajnih promena (ekstrahovan je manji broj faktora, prva glavna komponenta objašnjava veći procenat varijanse, i Katelov Scree test ukazuje jasnije na jednodimenzionalnost instrumenta) pri analizi podataka prikupljenih tokom drugog merenja u odnosu na prvo (videti Tabele 1. i 2., i Grafikone 1. i 2.).

Tabela 2. Dimenzionalnost instrumenata pri drugom testiranju na osnovu GutmanKajzerovog kriterijuma

\begin{tabular}{|c|c|c|c|c|c|}
\hline \multirow[t]{2}{*}{ Instrumenti } & \multirow[t]{2}{*}{ Br. GK } & \multicolumn{2}{|c|}{$\lambda$-svojstvene vrednosti } & \multicolumn{2}{|c|}{$\%$ varijanse } \\
\hline & & IGK & (II GK) & I GK & (II GK) \\
\hline SPROSIT & 5 & 4.022 & $(2.784)$ & 23.7 & $(16.4)$ \\
\hline SDU & 4 & 7.874 & $(1.585)$ & 49.2 & (9.9) \\
\hline SOD & 5 & 2.451 & $(2.394)$ & 20.4 & (19.9) \\
\hline VIDO & 1 & 4.695 & (.910) & 58.7 & (11.4) \\
\hline VRPI & 2 & 2.485 & $(1.152)$ & 41.4 & (19.2) \\
\hline PRAVA & 3 & 5.126 & $(1.290)$ & 51.3 & (12.9) \\
\hline
\end{tabular}

Značenje skraćenica u tabeli: SPROSIT S - upitnik namenjen proceni samopoštovanja; SDU Upitnik za procenu samoodređenja; SOD - Upitnik za procenu samoodlučivanja; VIDO - Intervju za procenu vršenja izbora i donošenja odluka; VRPI - Intervju za procenu nivoa usvojenosti veština rešavanja problema; PRAVA - Upitnik za procenu svesti o sopstvenim pravima; Br. GK - broj glavnih komponenti; I GK - Prva glavna komponenta; II GK- Druga glavna komponenta

U Tabeli 3. prikazane su psihometrijske karakteristike ispitivanog seta instrumenata, paralelno za prvo i drugo merenje, kao i test-retest pouzdanost..

Kao što se može videti, i za pretest i za posttest za ceo set instrumenata podaci ukazuju na zadovoljavajuće visoku reprezentativnost instrumenata.

Međutim, između pretesta i postesta postoji primetna razlika u koeficijentima pouzdanosti, kao i u merama homogenosti instrumenata.

Što se tiče pouzdanosti, i pri prvom i pri drugom merenju registrovani su zadovoljavajuće visoki koeficijenti pouzdanosti (i $\alpha$ i $\beta$ koeficijenti), međutim, evidentno su niži koeficijenti pouzdanosti pri drugom merenju, izuzev za instrument PRAVA, koji je u drugom merenju pokazao značajno veći koeficijent pouzdanosti. Pored toga, registrovan je značajan pad mera homogenosti $u$ drugom merenju, i to za sve instrumente, izuzev PRAVA, kod koga je homogenost veća. 
Boban Petrović, Katarina Tadić, Duška Stojisavljević

Tabela 3. Metrijske karakteristike instrumenata

\begin{tabular}{|c|c|c|c|c|c|c|c|c|c|}
\hline \multirow[t]{2}{*}{ Instrumenti } & \multicolumn{2}{|c|}{$\mathrm{KMO}-\Psi 1$} & \multicolumn{2}{|l|}{$a$} & \multicolumn{2}{|l|}{$\beta$} & \multicolumn{2}{|l|}{ hl } & \multirow{2}{*}{$\begin{array}{l}\text { T-R } \\
\text { pouzda- } \\
\text { nost }\end{array}$} \\
\hline & Pre & Post & Pre & Post & Pre & Post & Pre & Post & \\
\hline SPROSIT & .97 & .90 & .81 & .67 & .89 & .80 & .26 & .11 & .57 \\
\hline SDU & .99 & .98 & .95 & .93 & .95 & .93 & .56 & .45 & .46 \\
\hline SOD & .91 & .72 & .74 & .60 & .83 & .65 & .19 & .11 & .40 \\
\hline VIDO & .99 & .97 & .94 & .90 & .94 & .90 & .67 & .52 & .65 \\
\hline VRPI & .97 & .78 & .90 & .71 & .91 & .72 & .61 & .28 & .70 \\
\hline PRAVA & .86 & .97 & .43 & .86 & .77 & .89 & .07 & .38 & .19 \\
\hline
\end{tabular}

Značenje skraćenica u tabeli: SPROSIT S - upitnik namenjen proceni samopoštovanja; SDU Upitnik za procenu samoodređenja; SOD - Upitnik za procenu samoodlučivanja; VIDO - Intervju za procenu vršenja izbora i donošenja odluka; VRPI - Intervju za procenu nivoa usvojenosti veština rešavanja problema; PRAVA - Upitnik za procenu svesti o sopstvenim pravima; KMO- $\Psi 1$ Kaiser-Mayer-Olkin,mera reprezentativnosti; a - Spe-Br-Kud-Rich-Guttm-Cronbah alfa - mera pouzdanosti; $\beta$ - Lord-Kaiser-Caffrey BETA- mera pouzdanosti; hl - Prosečna korelacija varijabli mera homogenosti; T-R pouzdanost - test-retest pouzdanost; Pre - pretest; Post - posttest

Test-retest pouzdanost je za dva instrumenta umerena, za tri zadovoljavajuće visoka, dok je za instrument PRAVA loša.

\section{Diskusija}

Princip socijalnog uključivanja, koji je jedan od vodećih principa aktuelnog odnosa društva prema različitim socijalno isključenim grupama, uključujući i osobe sa intelektualnim teškoćama, podrazumeva uključivanje osoba sa intelektualnim teškoćama u sve socijalne procese koji se tiču njih, podrazumevajući tu i procese evaluacije socijalnih i drugih usluga koje im zajednica pruža, ali i procese naučnog ispitivanja.

U tom smislu, sve su aktuelniji pokušaji primene instrumenata upitničkog tipa namenjenih samoproceni različitih psiholoških konstrukata, kao i usmeravanje pažnje ne samo na one aspekte ličnosti koji se konotiraju kao negativni (depresivnost, anksioznost, agresivnost, i dr.), već i na kompetentnosti kao i pozitivne aspekte ličnosti osoba sa intelektualnim teškoćama. Međutim, istraživanja koja su se bavila problematikom mogućnosti primene instrumenata upitničkog tipa daju dvosmislene informacije: od toga da postoje značajne teškoće u primeni i konstrukciji instrumenata (pre svega, problemi sa pouzdanošću, validnošću, izborom formata odgovora, i sl.), do onih koji ukazuju na adekvatne metrijske karakteristike instrumenata. Analizom zaključaka na koje ukazuju radovi i s jedne i s druge strane, ipak se mogu izvući neki zaključci i smernice u pogledu konstrukcije instrumenata i njihove primene na osobe sa 
intelektualnim teškoćama, koji povećavaju mogućnost dobijanja pouzdanijih i validnijih podataka.

Mogućnost dobijanja pouzdanih i validnih podataka ima svoju praktičnu implikaciju posebno u situaciji pokretanja i razvoja za Srbiju novog programa, odnosno, socijalne usluge, kao što je Samozastupanje osoba sa intelektualnim teškoćama, posebno u pogledu mogućnosti što adekvatnije evaluacije razvoja programa i unapređenja kompetentnosti korisnika.

U tom smislu, važno je ispitati mogućnost primene instrumenata upitničkog tipa namenjenih samoproceni kapaciteta za samozastupanje osoba sa intelektualnim teškoćama, odnosno, mogućnosti dobijanja pouzdanih podataka na osnovu ovog seta instrumenata.

Rezultati ovog istraživanja pokazali su da je, ukoliko se poštuju napred navedeni principi konstrukcije i primene instrumenata, moguće dobiti adekvatne mere pouzdanosti i unutrašnje validnosti instrumenata, odnosno, da je moguće primeniti instrumente upitničkog tipa u cilju samoprocene osoba sa intelektualnim teškoćama. Međutim, iako se može izvući ovakav zaključak, ipak je potrebno ukazati na neke specifičnosti koje su rezultati pokazali.

Pre svega, značajno je primetiti da su se instrumenti, sa izuzetkom 2 (SPROSIT i SOD), pokazali kao jednodimenzionalni, i u prvom i u drugom merenju. Međutim, kod instrumenata koji nisu jednoznačno jednodimenzionalni, odnosno, čija je dimenzionalnost jasnije narušena pri ponovljenom ispitivanju, došlo je i do primetnog narušavanja metrijskih karakteristika, pre svega homogenosti. U pogledu metrijskih karakteristika, najstabilnijom se pokazala reprezentativnost instrumenata, $u$ pogledu koje $u$ ponovljenom merenju nije došlo do promena koje bi diskvalifikovale instrumente.

Međutim, došlo je do vidnijih promena u pouzdanosti ajtema, i to uzimajući u obzir obe mere pouzdanosti (alfa i beta). Ovakav rezultat je nađen i u drugim istraživanjima (Tailor, 2002; Petrović, 2008). Međutim, rukovodeći se vrednošću test-retest pouzdanosti, može se reći da u principu ovo snižavanje vrednosti mera pouzdanosti ne diskvalifikuje instrumente kao takve, već pre sugeriše njihove korekcije.

Najdrastičnije promene pojavile su se u pogledu homogenosti instrumenata (značajno niže mere homogenosti pri drugom merenju); i upravo iz ovih podataka se mogu pretpostaviti mogući razlozi slabijih metrijskih karakteristika pri drugom merenju, a koji se tiču uslova prikupljanja podataka.

U oba slučaja prikupljanja podataka, ispitanici su bili isti i uputstvo za primenu instrumenata nije se razlikovalo; međutim, terenski uslovi su nametnuli 2 
značajne razlike; različiti uslovi ispitivanja, te donekle različiti ispitivači (uključujući i broj ispitivača; u prvom ispitivanju bilo ih je 5, a u drugoj 8). Stoga je moguća pretpostavka da su se ove razlike odrazile i na kvalitet prikupljenih podataka. Naravno, moguća je i pretpostavka da je uzrok nekonzistentnosti i način odgovaranja ispitanika (dosadašnji nalazi ukazuju na značajan problem sa stilom i načinom odgovaranja osoba sa intelektualnim teškoćama); međutim, skloniji smo pretpostavci da je presudniju ulogu odigrala varijabilnost $u$ uslovima ispitivanja. Naravno, i veličina uzorka je takođe značajan faktor; međutim, u ovom ispitivanju nije se moglo doći do većeg uzorka iz razloga koji su nametnuti kontekstom realizacije programa samozastupanja.

Posebno je značajno zapaziti da je došlo i do promena u pravcu veće adekvatnosti instrumenta namenjenog proceni svesti o sopstvenim pravima; pri prvom merenju, analiza glavnih komponenti je sugerisala veći broj dimenzija ovog kratkog instrumenta, i metrijske karakteristike su bile nezadovoljavajuće; međutim, pri prvom merenju, ajtemima ovog instrumenta bila je pridružena dvostepena (da/ne) skala; pri drugom merenju, promenjen je format odgovora, i ajtemima je pridružena trostepena skala u skladu sa napred navedenim principima konstrukcije skale. Rezultati su pokazali adekvatnije metrijske karakteristike ovog instrumenta, jer je povećana i mogućnost šireg zahvata varijanse odgovora ispitanika.

\section{Zaključci}

U skladu sa svim napred rečenim, može se izvući opšti zaključak da se, kada se radi o primeni instrumenata upitničkog tipa namenjenih samoproceni osoba sa intelektualnim teškoćama, može preporučiti da se u što je većoj meri moguće standardizuju uslovi i kontekst ispitivanja: počev od spoljašnjih fizičkih okolnosti u kojoj se ispitivanje odvija, te personalnih karakteristika i obučenosti samog ispitivača, preko kontrolisanja stanja i raspoloženja ispitanika osobe sa intelektualnim teškoćama, do uputstva i načina primene instrumenata. Naravno, potrebno je uzeti u obzir i napred navedene preporuke za konstrukciju samih instrumenata (kratki, jednodimenzionalni instrumenti, sa trostepenom skalom, koji se administriraju po principu strukturiranog intervjua). Pored toga, potrebno je ispitati i kriterijumsku validnost instrumenata, kao i njihovu konvergentnu i divergentnu validnost u odnosu na instrumente koji mere slične konstrukte, i koji su dizajnirani za primenu na opštoj, odn. tipičnoj populaciji. Ukoliko se navedene preporuke uzmu u obzir, i ukoliko rezultati budućih istraživanja budu u skladu sa pretpostavkama proizašlim iz ovog rada, postoji mogućnost da podaci dobijeni administracijom samoopisnih upitnika osobama sa IT budu pouzdani i validni. 


\section{Reference}

Atkinson, D. (2002). Self-advocacy and research. In B. Gary \& R. Jackson (Eds.), Advocacy and learning disability (pp. 120-136). London and Philadelphia: Jessica Kingsley Publisher.

Bilić, M. (2000). Inicijalni upitnik za procenu kapaciteta i potreba osoba sa inteleltualnim teškoćama pri deinstitucionalizaciji, interni materijal, Udruga za promicanje inkluzije, Zagreb.

Campbell, V. (2001). Measurement of disability in special populations: People with limited cognitive functioning. NewYork: International Seminar on the Measurement of Disability.

Clark, G.M., \& Patton, J.R. (1997). Transition planning inventory (TPI). Austin: PRO-ED.

Cuthill, F.M., Espie, C.A., \& Copper, S.A. (2003). Development and psychometric properties of the Glasgow Depression Scale for people with a Learning Disability-Individual and carer supplement versions. British Journal of Psychiatry, 182, 347- 353.

Davis JP, Judd FK, \& Herrman H. (1997a). Depression in adults with intellectual disability. Part 1: A review. Australian and New Zealand Journal of Psychiatry, 31, 232-42.

Davis JP, Judd FK, Herrman H. (1997b). Depression in adults with intellectual disability. Part 2: A pilot study. Australian and New Zealand Journal of Psychiatry, 31, 243-51.

Douma, J.C.H., Dekker, M.C., Verhulst, F.C., \& Koot, H.M. (2006). Selfreports on mental health problems of youth with moderate to borderline intellectual disabilities. Journal of the American Academy of Child E Adolescent Psychiatry, 45, 1224-1231.

Esbensen, A. J., Rojahn, J., Aman, M.G., \& Ruedrich, S. (2003): Reliability and validity of an assessment instrument for anxiety, depression, and mood among individuals with mental retardation. Journal of Autism and Developmental Disorders, 33, 617-629.

Finlay, W.M., \& Lyons, E. (2001). Methodological issues in interviewing and using self-report questionnaires with people with mental retardation. Psychological Assessment, 13, 319-35. 
Garaigordobil, M., \& Pérez, J. I. (2007). Self-Concept, Self-Esteem and Psychopathological Symptoms in Persons with Intellectual Disability. The Spanish Journal of Psychology, 10, 141-150.

Gustafsson, C. (2003). Intellectual disabilities and mental health problems Evaluation of two clinical assessment instruments, occurrence of mental health problems and psychiatric care utilization. Uppsala: Acta Universitatis Upsaliensis.

Hartley S.L, \& MacLean, W.E.Jr. (2006). A review of the reliability and validity of Likert-type scales for people with intellectual disability, Journal of Intellectual Disabilities, 50, 813-27.

Heal L.W., \& Sigelman, C.K. (1995). Response biases in interviews of individuals with limited mental ability. Journal of Intellectual Disability Research, 39, 331-40.

Hrnjica, S. (1991). Ometeno dete, Zavod za udžbenike i nastavna sredstva, Beograd.

Hurley, A. D. (2006). Mood disorders in intellectual disability. Current Opinion in Psychiatry, 19, 465-469.

Knežević G., i Momirović K. (1996). RTT9G - program za analizu metrijskih karakteristika kompozitnih mernih instrumenata. U: Kostić, P. (urednik): Merenje u psihologiji - primena računara. Vol. II. (pp. 37-57). Beograd: Institut za kriminološka i sociološka istraživanja.

Kraljević, M. (2001). Evaluacija programa osposobljavanja osoba s mentalnom retardacijom za samozastupanje. Nepublikovani magistarski rad. Edukacijsko-Rehabilitacijski fakultet Sveučilišta u Zagrebu, Zagreb.

Lindsay, W.R., Rzepecka, H., \& Law, J. (2007). An exploratory study into the use of the five factor model of personality with individuals with intellectual disability. Clinical Psychology and Psychotherapy, 14, 428-437.

Matikka, L.M., \& Vesala, H.T. (1997). Acquiescence in quality-of-life interviews with adults who have mental retardation. Mental Retardation, $35,75-82$.

Meins, W. (1996). A new depression scale designed for use with adults with mental retardation. Journal of Intellectual Disability Research, 40, 222-6.

Meins, W. (1993). Assessment of depression in mentally retarded adults: reliability and validity of the Children's Depression Inventory (CDI). Research of Developmental Disabilities, 14, 299-312. 
Mindham, J., \& Espie, C.A. (2003). Glasgow Anxiety Scale for people with an intellectual disability (GAS-ID): Development and psychometric properties of a new measure for use with people with mild intellectual disability. Journal of Intellectual Disability Research, 47, 22-30.

Parker, C., Goedhart, F., \& Gomez, G. (2004). Partners for better policies: a manual for mainstreaming. Brussels: IE, GIP, OSI.

Petrović, B. (2008). Konstrukcija i evaluacija instrumenta za procenu ličnosti osoba sa intelektualnim teškoćama baziranog na petofaktorskom modelu. Neobjavljeni master rad. Odeljenje za psihologiju, Filozofski fakultet, Beograd.

Petrović, B., i Novak, J. (2009). Osnovne metrijske karakteristike seta upitnika za samoprocenu kapaciteta za samozastupanje OSIT - preliminarni rezultati, Knjiga rezimea sa XV naučnog skupa Empirijska istraživanja u psihologiji, Filozofski fakultet, Beograd.

Ramirez, S. (2005). Evaluating acquiescence to yes-no questions in fear assessment of children with and without mental retardation. Journal of Developmental and Physical Disabilities, 17, 337-343(7).

Reynolds, W. M., \& Baker, J.A. (1988). Assessment of depression in persons with mental retardation. American Journal of Mental Retardation, 93, 93-103.

Sigelman, C.K., Schoenrock, C.J., Spanhel, C.L., Hromas, S.G., Winer, J.L., Budd, E.C., \& Martin, P.W. (1980). Surveying mentally retarded persons: responsiveness and response validity in three samples. American Journal of Mental Deficiency, 84, 479-86.

Sigelman, C.K., Budd, E.C., Winer, J.L., Schoenrock, C.J., \& Martin, P.W. (1982). Evaluating alternative techniques of questioning mentally retarded persons. American Journal of Mental Deficiency, 86, 511-8.

Tailor, J.L. (2002). A review of the assessment and treatment of anger and aggression in offenders with intellectual disability. Journal of Intellectual Disability Research, 46, 57-73.

Torr, J. (2003). Personality disorder in intellectual disability: Developmental disorders. Current Opinion in Psychiatry, 16, 517-521.

Wehmeyer, M.L. (1994). Reliability and acquiescence in the measurement of locus of control with adolescents and adults with mental retardation. Psychological Reports, 75, 527-37. 
Wyngaarden, M. (1981). Interviewing mentally retarded persons: Issues and strategies. Monograph of the American Association of Mental Deficiency, $4,107-13$.

\section{Prilozi}

Scree Plot SPROSIT

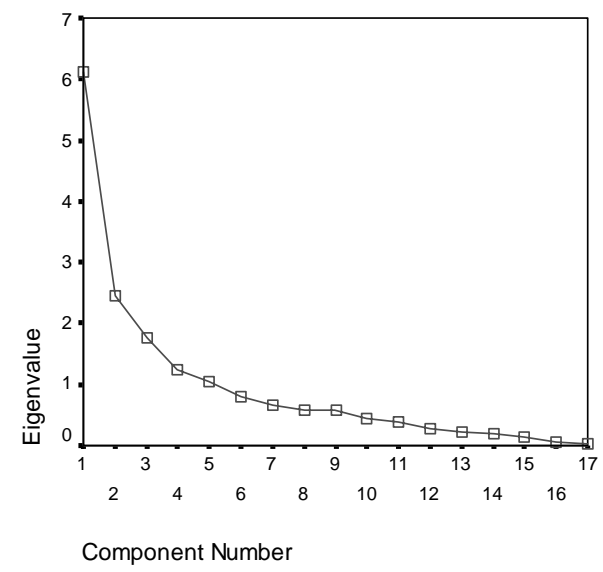

Scree Plot SDU

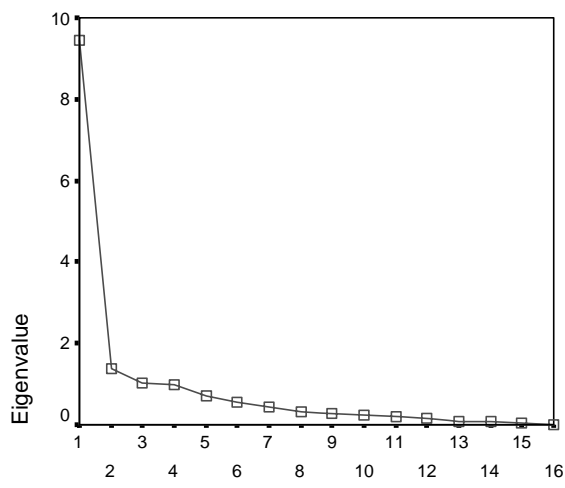

Component Number
Scree Plot SOD

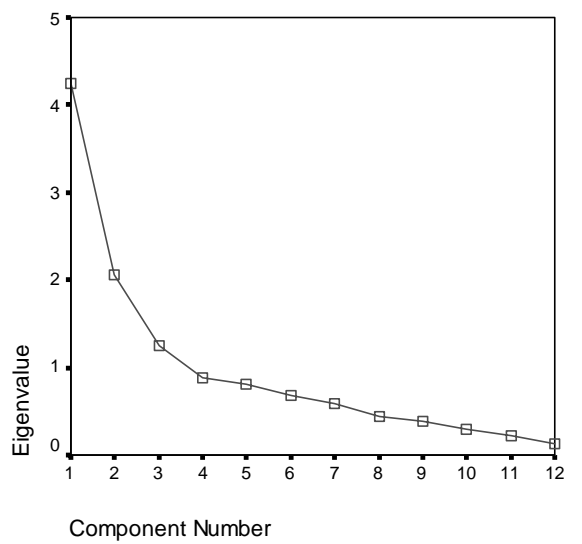


Scree Plot VIDO

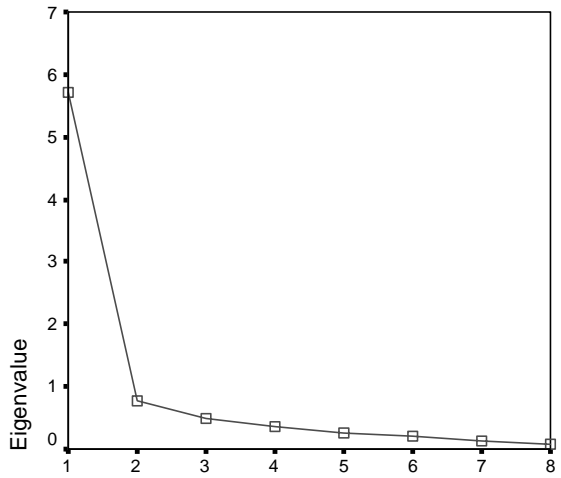

Component Number
Scree Plot VRPI

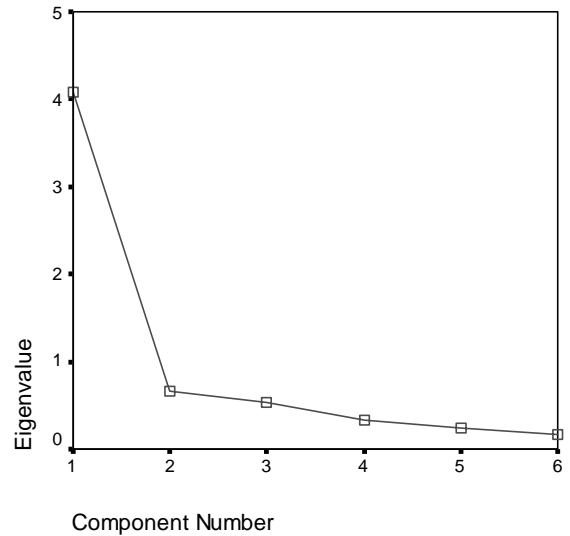

Scree Plot PRAVA

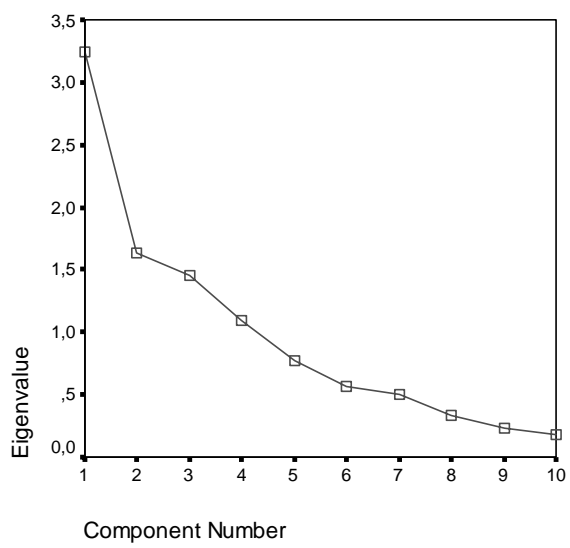

Grafikon 1. Dimenzionalnost konstrukata pri pretestu 
Boban Petrović, Katarina Tadić, Duška Stojisavljević
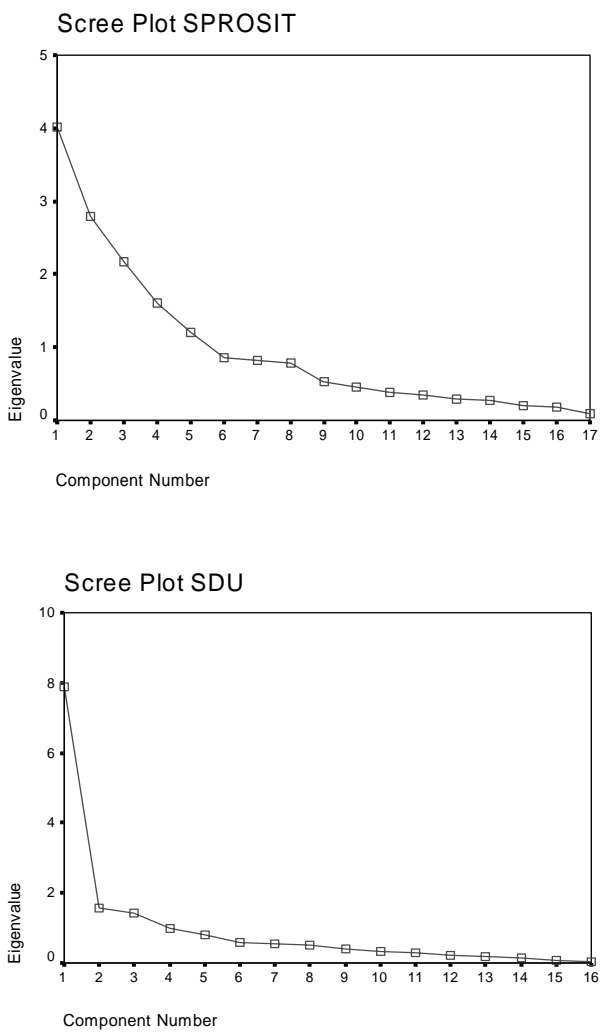
Mogućnosti samoprocene osoba sa intelektualnim teškoćama putem upitnika

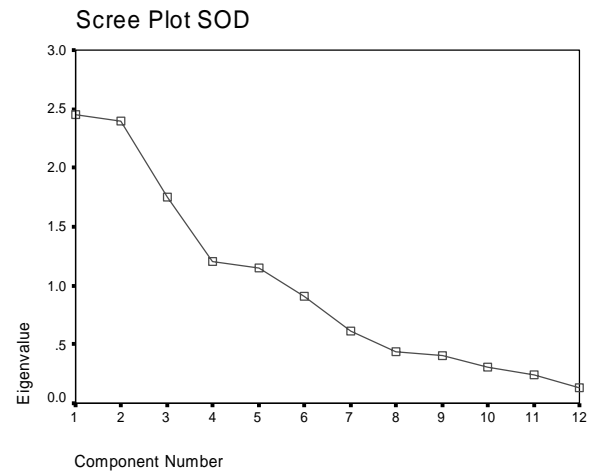

Scree Plot VIDO

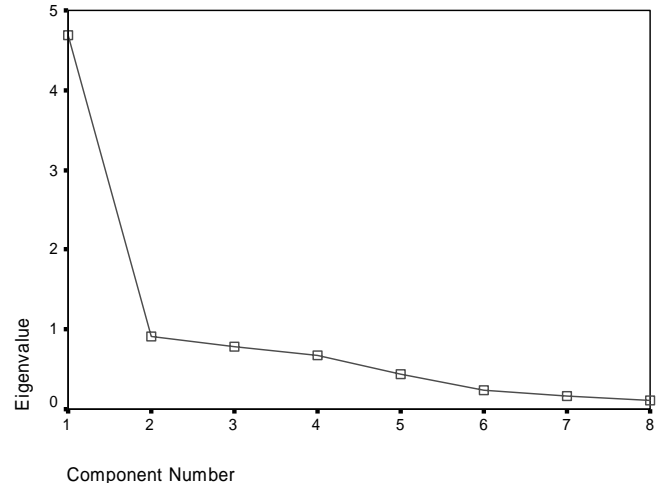


Boban Petrović, Katarina Tadić, Duška Stojisavljević

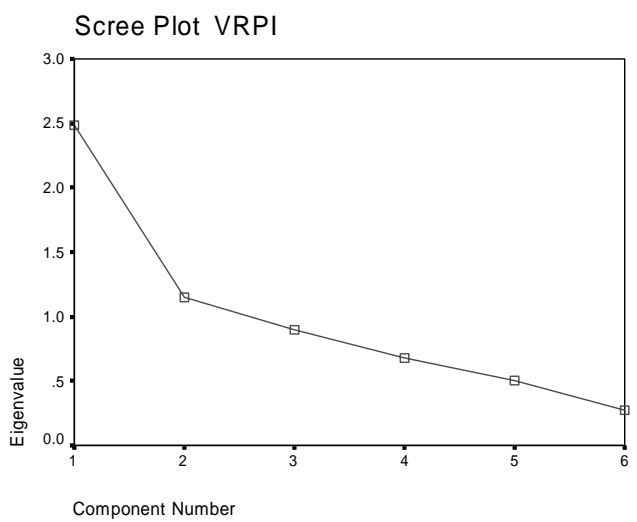

Scree Plot PRAVA

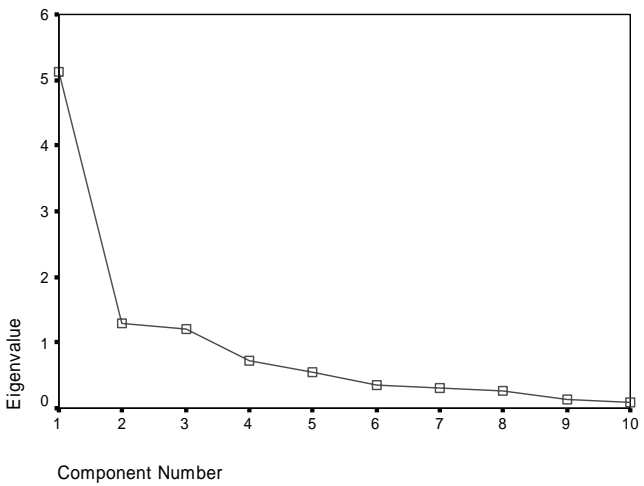

Grafikon 2. Dimenzionalnost konstrukata pri retestu 


\title{
Abstract
}

\section{POSSIBILITIES FOR USING SELF-REPORT QUESTIONAIRRES IN ASSESSMENT OF SELF-ADVOCACY CAPACITIES OF PEOPLE WITH INTELLECTUAL DISABILITIES}

\author{
Boban Petrović, Katarina Tadić, Duška Stojisavljević
}

In latest decade, in according with philosophy of inclusion, increasing attention paid to the possibility of using self-report questionnaire for people with intellectual difficulties in terms of different psychological constructs. However, the data are different, from those that indicate the impossibility of obtaining reliable and valid answers to the questionnaires, to those who show that questionnaires designed for self-assessment of people with intellectual disabilities can have adequate reliability and validity.

The main goal of this research concerning the investigation of possibilities to obtain reliable and valid data on the basis of selfassessment of persons with intellectual disabilities in the set of instruments for the study of the capacities for self-advocacy.

In this sense, on the sample of 35 people with intellectual disabilities, different on the basis of sex, age, type and degree of difficulty, are applied set of 6 selfreport instruments for assessing: self-esteem, decision-making, making choice, problem solving, knowledge of rights and self-determination.

Data is analysed by principal component analysis, as well as RTT10G program for calculating of psychometric charasteristic of instruments.

The results show that, despite the mild violation of the characteristic and dimenzionality of instruemnts on the second measurement, instruments have adequate metric characteristics (representativeness, homogeneity and reliability) and dimensionality.

Therefore, it can make conclusion that there is a possibility for getting reliable and valid data on basis of application of self-report measurres for selfadvocacy capacities of people with intellectual disabilities assessment.

Key words: people with intellectual disabilities, self-advocacy, self-report questionairres, psychometric characteristic

Primljeno: 3. 7. 2009; prihvaćeno za štampu: 1. 11. 2009. 